\title{
EDITORIAL
}

\section{Más allá de la conciliación: hacia la corresponsabilidad}

\author{
Eva MaRÍa Blázquez Agudo \\ Directora de Femeris \\ Universidad Carlos III de Madrid \\ orcid id: 0000-0002-8214-1960
}

doi: https://doi.org/10.20318/femeris.2017.3755

Como ya se sabe, las mujeres asumen en mayor medida las labores de cuidado de la familia. Así, de acuerdo con los datos de la última encuesta de empleo, en España las mujeres dedican 4 horas y 7 minutos a estas actividades frente a 1 hora y 54 minutos que emplean los hombres. Cuando parecen superados los antiguos roles de reparto de las tareas de cuidado, por la inserción masiva de las trabajadoras en el mercado laboral, sin embargo, en gran parte siguen asumidas por las mujeres, realizando lo que se conoce como doble jornada (una en el lugar de trabajo y otra en el hogar familiar).

El hecho de que la mujer asuma más labores de cuidado conlleva que deba disponer de los medios que existen en el derecho laboral para tratar de conciliar sus dos vidas (la laboral y la familiar). De este modo, son las trabajadoras quienes utilizan mayoritariamente los permisos regulados en la ley y en los convenios colectivos a estos efectos, así como la reducción de jornada y la excedencia por cuidado de hijos o familiares. Esta realidad las sitúa en una posición de desventaja en el mercado de trabajo, puesto que se valora en menor medida su actividad, con lo que, en general, acceden a peores trabajos y a salarios más reducidos que los trabajadores. En definitiva, la conciliación provoca su discriminación laboral indirecta.

Son, en cambio, las medidas que implican a los hombres en la vida familiar, las que benefician la integración laboral de la mujer. Cuantas más acciones se implanten en las empresas con el fin de que los trabajadores asuman las tareas de cuidado, mayor será el impacto en el índice de igualdad entre sexos en el mercado laboral. Esta idea se está apoyando desde las distintas instituciones internacionales.

*eagudo@der-pr.uc3m.es 
En el marco internacional, la Nueva Agenda para 2030 para el Desarrollo Sostenible del planeta establece 17 Objetivos de Desarrollo Sostenible (ODS) dirigidos a todos los países. El Quinto ODS promulga la lucha por la consecución de la igualdad de género y el empoderamiento de todas las mujeres y las niñas. Una de sus metas es poner en valor las labores de cuidado, entre ellas las de las mujeres que tratan de conciliar la vida laboral y familiar. En este contexto, se indica que son necesarias acciones públicas con el fin de promover la responsabilidad compartida sobre las tareas de cuidado entre hombres y mujeres.

De acuerdo con lo señalado, era esperable que los Pilares Europeos sobre derechos sociales pusieran en evidencia que el derecho a la conciliación de la vida familiar y laboral debe emplearse con el fin de resolver la infrarrepresentación de la mujer en el mercado laboral, pero yendo más allá de la idea de la conciliación para apostar por la corresponsabilidad.

Recientemente la Comisión Europea ha planteado interesantes propuestas dentro del objetivo de la corresponsabilidad, destacando los importantes beneficios que dichas acciones pueden tener en el incremento de la competitividad y la productividad de la empresa.

Entre estas medias, por ejemplo, se ha recomendado el reconocimiento de permisos de paternidad de, al menos, 10 semanas por nacimiento de hijo, en el que se abonará una prestación similar a la reconocida en caso de baja por enfermedad. En España, desde 2017 se reconocen 4 semanas de paternidad, donde se recibe un beneficio del 100\% del salario. Habría que plantear cómo se podría reconocer un derecho así, que seguramente pasaría por la reducción retributiva de la prestación a partir de la quinta semana.

Como el permiso de maternidad tiene una duración de 16 semanas, es posible que la primera opción que se baraje sea reducir este permiso para elevar el de paternidad. Algo similar a lo que ocurre con el permiso por adopción o acogimiento que tiene una duración total de 16 (maternidad) más 4 (paternidad) semanas, esto es, 20 semanas, que se dividen libremente entre los progenitores. Desde este ejemplo, podría proponerse que el total de las 20 semanas se dividiese en 10 y 10 para cada progenitor.

Obviamente esta no es la solución. El permiso de maternidad tiene una doble función, el cuidado de los hijos y la recuperación de la salud de la mujer, de forma que no es admisible su reducción, en ningún caso. De hecho, las primeras 6 semanas son obligatorias a estos efectos, y luego las otras 10 tienen un objetivo de atención del recién nacido. En el caso de que se ampliase el permiso de paternidad de acuerdo con lo recomendado por la UE se conseguiría repartir equitativamente las tareas de cuidado, puesto que ambos tendrían 10 semanas para dedicarse a estas labores.

Se puede alegar los efectos perniciosos en las arcas de la Seguridad Social, no obstante, la tasa media de hijos en España es especialmente baja, de modo que no tendría gran implicación de costes, y sí unos grandes efectos sociales. Si los dos progenitores pueden disfrutar de idénticos derechos, se reducirán otro tipo de medidas empleadas para atender a las necesidades familiares y se conseguirá la igualación progresiva de las trabajadoras con los trabajadores en el mercado laboral.

En otro orden de cosas, los Pilares europeos también recomiendan la regulación de un permiso parental para cada uno de los progenitores, no transferible, de hasta 4 meses a disfrutar hasta que los hijos alcancen 12 años. Se fundamenta en facilitar la flexibilidad laboral 
cuando sea preciso. En este caso, parece que el coste económico (una prestación similar a la abonada por baja por enfermedad) recaería en la Seguridad Social con lo que de nuevo hay que volver a poner en evidencia los problemas de financiación que se pueden causar.

En ambos casos, se podría establecer un derecho universal para los trabajadores, que no se financie por cotizaciones, sino por impuestos, dado que se trata de conseguir un objetivo social de cooperar con la igualdad del mercado laboral. No hay que olvidar que el propio sistema actual tiene mecanismos para compensar las lagunas de cotización de las trabajadoras que fueron madres y para premiarlas por tal motivo a través de un complemento por maternidad que se añade a sus pensiones. Estas medidas vendrían a completar este elenco de acciones.

Asimismo, se apuesta por promover la flexibilidad laboral en el tiempo (horario y reducción de jornada) y lugar de trabajo dirigida a los progenitores con hijos menores de 12 años, que sin lugar a duda deberían ofrecerse a todos los trabajadores con el fin de que todos pudiesen conciliar su vida personal, laboral y familiar, evitando el estigma de las mujeres que deben usarlas para atender a sus cargas familiares.

Obviamente la implantación de todas estas acciones colaboraría con la consecución de la igualdad de trabajadores y trabajadoras en el mercado laboral. En la legislación española no existe normativa que se dirija a este objetivo, excepto el mencionado permiso de paternidad. Pero, sí se encuentran ejemplos en otros Estado de la Unión Europea: en Portugal que reconoce un aumento de 30 días del descanso parental si los progenitores acuerdan compartirlo; en Austria se incrementa la cuantía del beneficio concedido por hijo cuando su cuidado lo asume el padre; y en Alemania se concede una prestación similar dirigida solo a los padres cuidadores.

Pero, no solo las entidades públicas tienen obligaciones al respecto, también las empresas pueden fomentar la corresponsabilidad. En España, hay aún pocas propuestas, pero ya podemos encontrar algunas en el ámbito de los Planes de Igualdad. Medidas que van desde la simple sensibilización en la materia, que a veces dan un paso más, tratando de animar a la participación en las labores relativas a las cargas familiares.

Hay otras buenas prácticas que amplían los derechos legales de los padres en relación a las actividades previas al parto. En algunos otros casos, se permite la ampliación de tiempo dedicado al cuidado más allá del derecho a la paternidad, por ejemplo, reconociendo permisos no remunerados exclusivamente a los hombres en caso de nacimiento; o alterando el régimen legal de acuerdo entre las partes (empresa y trabajador) en materia de determinación de las vacaciones anuales, en ambos casos permitiendo acumular estos con el permiso de paternidad. Terminado este beneficio, a veces se reconoce al padre la posibilidad de flexibilizar el horario de trabajo durante los 2 meses inmediatamente posteriores al nacimiento de un hijo, o se concede un permiso retribuido exclusivamente a los varones por el tiempo necesario para acompañar a sus hijos a las consultas del médico.

Por último, es destacable una medida dirigida a promocionar la reducción de la jornada por cuidado de hijo entre los trabajadores, teniendo en cuenta que su uso es casi en su totalidad femenino. Si un trabajador varón solicita esta medida, la reducción de su sa- 
lario no será aminorado proporcionalmente según la disminución de la jornada, sino que, mejorando la ley, podrá mantener un porcentaje de remuneración superior.

En conclusión, no parece adecuado reivindicar más medidas de conciliación, que finalmente solo aprovechan las mujeres. Al promocionar estas, se provoca un efecto de discriminación indirecta, puesto que reduce sus posibilidades reales en el mercado laboral, afectando a su contratación, su salario y su promoción. Sin embargo, con la implicación directa de los hombres en las cargas familiares con medidas destinadas a este objetivo, se conseguirá su paulatina implicación en la vida familiar lo que, consecuentemente, traerá la igualación en el mercado de trabajo de los hombres y las mujeres. 